\section{THE COCAINE 'BODY-PACKER' SYNDROME: DIAGNOSIS AND TREATMENT}

Sir,

A 55-year-old African man was found unconscious at Al Doha airport in the state of Qatar at 11:00 am. The patient was unconscious, tachypnic, pupils were fixed and dilated, blood pressure $150 / 90 \mathrm{mmHg}$, Pulse $105 / \mathrm{min}$, and the oral temperature was $37.0^{\circ}$ C. Because the individual was alone and unresponsive no past medical history was obtained. The patient was taken from the airport to the accident and emergency (A\&E) department. Upon arrival to the A\&E department he developed generalized seizures. On examination, the patient was unconscious, tachypnic, afebrile, pupils were fixed and dilated, blood pressure 150/ $90 \mathrm{mmHg}$, Pulse $105 / \mathrm{min}$ and the oral temperature was $37.0^{\circ} \mathrm{C}$. Arterial blood gas analysis at room air showed $\mathrm{pH}=7.468, \mathrm{pO}_{2}$ $=65 \mathrm{~mm} \mathrm{Hg}, \mathrm{pCO} 2=30 \mathrm{~mm} \mathrm{Hg}, \mathrm{HCO} 24$ $\mathrm{mmol} / \mathrm{L}$.

The haemoglobin, platelets, leucocyte count, blood sugar, serum electrolytes, and serum creatinine, were within normal range. Liver function test and coagulation profile were normal, as well as brain computed tomography scans. The remainder of the examination was unremarkable. He was intubated and admitted to medical intensive care unit.

Plain abdomen X-ray showed two packets in the stomach [Figure 1a] and one packet in the rectum [Figure 1b]. The packets were removed by an endoscopy. [Figure 2a] showed one of the removed packets from the stomach. [Figure
$2 b]$ the packet removed from the rectum. Each packet weight approximately 80 grams.

After removing the packets, the patient was treated conservatively, he regained his consciousness after five days. Analysis of the materials in the packets revealed cocaine which was also detected in the urine. The patient was seen by a psychiatrist and later on he was taken to the prison.

Body packers are people who illegally carry drugs, mostly cocaine and heroin, concealed within their bodies. The packets can be made of various materials, but most often are condoms, which are easily available on the market. The packets are inserted in the mouth, rectum or vagina in order to get across borders without being detected.

After the body packer swallows these packets,

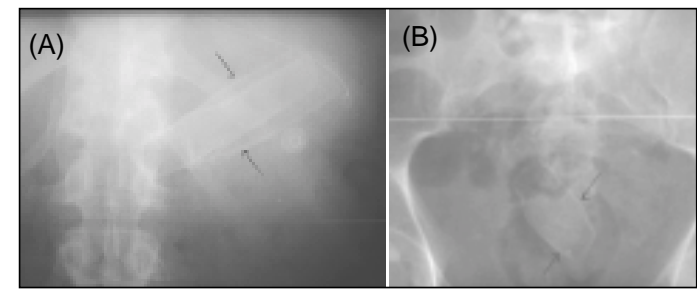

Figure 1: (A) Plain abdomen $X$-ray showed two packets in the stomach. (B) Plain abdomen X-ray showed one packet in the rectum

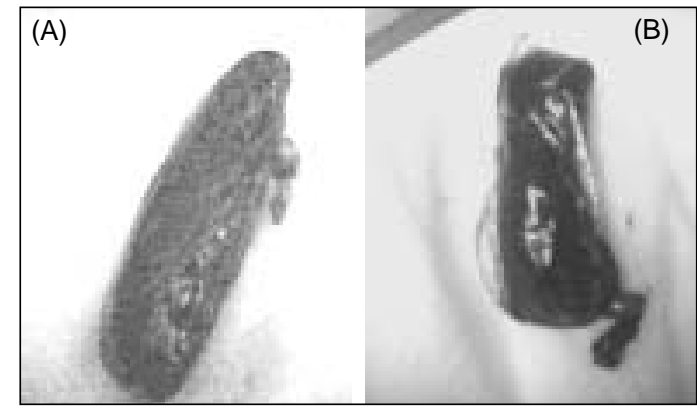

Figure 2: (A) This packet removed from the stomach. (B) This packet removed from the rectum
Constipating agents, such as diphenoxylate or loperamide, are frequently used..$^{[1]}$ Transit times may be as brief as one or two days or as long as two to three weeks. After entering the country of destination, body packers use laxatives, cathartics, or enemas to help pass their cargo rectally. ${ }^{[2]}$

Body packers usually present to health care providers for one of three reasons, ${ }^{[3]}$ : druginduced toxic effects, intestinal obstruction, or medical assessment after detention or arrest. This patient developed life threatening cocaine toxicity from leakage of the contents of these packages into his bowels.

A detailed history should be obtained. However, body packers are often dishonest historians. In rare cases, like in this case, patients may be unable to provide a history owing to profound drug-induced toxic effects. Body packing should be suspected in anyone with signs of drug-induced toxic effects after a recent arrival on an international flight or when there is no history of recreational drug use.

Cocaine toxicity causes anxiety, dilated pupils, diaphoresis, tachycardia, and hypertension, followed by hyperthermia, seizures, and cardiovascular collapse. Patients suspected of being body packers require radiographic evaluation.

Patients who are asymptomatic can be treated conservatively and expectantly until the packets pass. Whole bowel irrigation (WBI) should be started with a polyethylene glycol/ electrolyte lavage solution. ${ }^{[4,5]}$

Although endoscpic removal of packets is acceptable, It has generally become accepted that cocaine body packers who show signs of cocaine toxicity or gastrointestinal obstruction should undergo immediate emergency surgery.

\section{REFERENCES}

1. McCarron MM, Wood JD. The cocaine 'body packer' syndrome: diagnosis and treatment. JAMA 1983;250:1417-20.

2. Wetli CV, Mittleman RE. The "body-packer syndrome" - toxicity following ingestion of illicit drugs packaged for transportation. J Forensic Sci 1981;26:492-500

3. Bulstrode N, Banks F, Shrotria S. The outcome of drug smuggling by 'body-packers' — the British experience. Ann R Coll Surg Engl 2002;84:358.

4. Farmer JW, Chan SB. Whole body irrigation for contraband bodypackers. J Clin Gastroenterol 2003;37:147-50.

5. Hoffman RS, Smilkstein MJ, Goldfrank LR. Whole bowel irrigation and the cocaine body packer: a new approach to a common problem. Am J Emerg Med 1990;8:523-7.

F. Y. KHAN Department of Medicine, Hamad General Hospital, Doha, Qatar

Correspondence

FY Khan, Senior Specialist, Department of Medicine, Hamad General Hospital, P.O. Box 3050 E-mail: fakhanqal@yahoo.co.uk

\section{AN ELDERLY MAN WITH} DYSPHAGIA AND DYSARTHRIA

Sir,

An 81-year-old man was admitted to hospital with a 2-day history of slurred speech and swallowing difficulty. There was no history of weakness in the limbs, diplopia or difficulty in breathing. He had enjoyed good health up until 